\title{
COVID-19 Pandemic Outbreak: An Analysis of the Healthcare, Socio-Economic Challenges in Pakistan
}

\author{
Tabassum Parveen, Wenchang Wang, Wei Hao* \\ College of Public Administration, Shanxi Agricultural University, Jinzhong, China \\ Email: wwc0529905@163.com, ^sxauhw@126.com
}

How to cite this paper: Parveen, T., Wang, W. C., \& Hao, W. (2021). COVID-19 Pandemic Outbreak: An Analysis of the Healthcare, Socio-Economic Challenges in Pakistan. Open Journal of Social Sciences, 9, 245254.

https://doi.org/10.4236/jss.2021.93016

Received: February 18, 2021

Accepted: March 19, 2021

Published: March 22, 2021

Copyright $\odot 2021$ by author(s) and Scientific Research Publishing Inc. This work is licensed under the Creative Commons Attribution International License (CC BY 4.0).

http://creativecommons.org/licenses/by/4.0/

\begin{abstract}
Pakistan is one of the countries most affected by the COVID-19 epidemic in South Asia. The purpose of this paper is on the way to examine the medical, socio-economic challenges facing the nation. The study design includes nationwide COVID-19 data at the country level that were paired with the distressed population of healthcare, socio-economic status. Qualitative information and quantitative data from disparate sources have been used from secondary sources. From official sources by using data, guesses have been made of the defenseless population. Our analysis shows that there are inadequate well-resourced hospitals, insufficient challenging services, insufficient understanding, incorrect knowledge, attitudes and practices to guidelines, poverty and dangerous employment are the main issues in the spread of COVID-19. Stern law implementation measures should be made and ensuring that people follow the rules can help to lessen the spread of infection. Satisfactory medical facilities are crucial for founding appropriate health services.
\end{abstract}

\section{Keywords}

COVID-19, Socio-Economic Encounters, Healthcare Facilities, Pakistan

\section{Introduction}

The 2019-2020 novel coronavirus SARS-CoV-2 epidemic success at changed times, with changeable strength global. Coronavirus epidemic is a main hazard to the worldwide population, with confirmed cases and deaths assessed on December 28, 2020 at 79,515,525 and 1,757,947 individually. The first spread of coronavirus infection happened in Wuhan, Hubei province in China (Zhong et al., 2020). This virus has a high transformation rate and its huge spread infects 
people very fast. Severe acute respiratory syndrome SARS COVID-19 is a main impediment that happens to the patient suffering from coronavirus disease. Nearby 219 countries have been pretentious by this fatal virus follow-on the growth in the figure of cases. World Health Organization (WHO) has declared COVID19 as an epidemic because of its outstanding lay out all over the world. On the report of countries, Americas and Europe have been testified to have the maximum number of COVID-19 cases 34,630,861 and 25,271,882 individually. Until November 28 2020, the five countries with the maximum number of confirmed COVID-19 cases all over the world are USA $(18,827,300)$, India $(10,207,871)$, Brazil $(7,465,806)$, Russian Federation $(3,030,248)$, France $(2,507,532)$ and UK $(2,256,009)$. USA (329,310), Brazil (190,795), India (147,901), Mexico (122,026), Italy $(71,620)$ and UK $(70,405)$ have the maximum figures of fatal cases. Thus, the overall number of deaths in China reached at 4748 while the confirmed cases attitude at 92,164 .

Pakistan is a highly populated developing (low and middle income) country in South Asia with an entire population of 212.2 million (Pakistan Labour Survey, 2017-18). Due to the spread of this virus, Pakistan is facing disaster. The COVID19 epidemic has a strong grasp in developed and developing countries has by now spread across Pakistan with the speediest lay out touching near to defenseless conditions (Iqbal \& Younas, 2020). In spite of, Pakistan is a closest country of China, the first patient of COVID-19 was confirmed three months later than in China, on February 262020 (Gul, 2020). Till 28th December 2020, the number of COVID-19 cases was 471,335 with the death toll rises to 9874 .

Pakistan is less defensive than the other countries, due to the high population density. As a result, the main challenge facing Pakistan is to limit new cases and reduce mortality and morbidity rates. The health and socio-economic influence of the condition is shocking in the country. If physical diversion measures are taken at the beginning of the pandemic, the health impact can be minimized. The main purpose of this research is to examine the health, and socio-economic encounters challenged by the nation in responding to the disaster triggered by the COVID-19 epidemic. The research also solves the problem of public complying with policies and practices to control the spread of the virus. The research also reports the problems related to guidelines and performs that are indispensable to be shadowed by the population in command to cover the spread of the virus.

\section{Methodology}

In this research, both quantitative and qualitative study methods have been put. As of secondary sources, writers' individual approximations/forecasts, evidence from newspaper articles, websites of WHO, Worldometer, National Institute of Health Islamabad and Centre for Disease Control and Prevention (NIHI and $\mathrm{CDC}$ ), Government of Pakistan (GoP), and relevant research organizations, data is used. By using data from authorized sources, guesses have been made of the 
defenseless population. They have been further added by data from other reviews and studies. From a variety of sources, Individual notes of social performance and qualitative data were gained. PubMed, Google scholars were examined for unique research papers on COVID-19 pandemic. The search was done from 26 February to December 28, 2020 to bring together data related to healthcare, socio-economic viewpoint of Pakistan. A sequences of main search relations was used in the method, such as, "COVID-19," "Coronavirus," "COVID19 Outbreak" for the findings of healthcare, social economic challenges in $\mathrm{Pa}$ kistan.

\section{The Data Analysis}

\subsection{Health Maintenance Provision}

Pakistan has approved around guidelines to reduce the spread of COVID-19 in agreement with the plans of the World Health Organization. These strategies include lifestyle changes, face masks, reduced mobility, social distancing and changes in cleaning habits. In calculation, the management and the secluded sectors are committed to raising people's awareness through the use of local media to enhance particular cleaning behavior. According to Mohammad Arslan Iqbal et al., it is believed that many people in Pakistan have insufficient knowledge about the spread, symptoms and signs of COVID-19. Since the spread COVID-19 epidemic, Pakistan's healthcare services have come across massive difficulties in treating patients. Serious problems continued in hospitals concerning the accessibility of ventilator provision services to treat COVID-19 patients. With a size of population of 220,892,340, the number of beds per 1,000 inhabitants is 0.6 , and the number of Intensive Care Unit (ICU) beds per 100,000 inhabitants is 0.8 (Government of Pakistan, 2020).

According to the World Health Organization's status report, as of June 27, 2020, there are 23,557 general hospital beds and 763 Intensive care units (ICUs) nationwide for the treatment of COVID-19 patients in Pakistan. Among them, patients in Islamabad only occupy 2362 (10.0\%) general hospital beds and 114 (14.9\%) Intensive Care Units (ICUs). As many infected people receive treatment at home, hospital beds are not fully occupied (Kakakhel et al., 2020). In a first few days, Pakistan needed medical facilities and suspicious samples were sent to China. Later three months of the COVID-19 epidemic in Pakistan, until the government of Pakistan received primers, test kits and equipment from other countries, few specific quarantine centers had imperfect diagnostic and treatment facilities. As of June 27, 2020, many test centers have opened in Pakistan (Khalid \& Sana, 2020).

Firstly, the testing facilities are inadequate, but over time, as the number of cases increases, the facilities are also enhanced. Over time, all governments and some private medical organizations across the country have begun testing for COVID-19 (Saqlain et al., 2020a). However, Pakistan's COVID-19 test report is $164 / 1$ million, which is still uncertain related with other countries in South Asia 
(Saqlain et al., 2020a). WHO continues to support Pakistan's Ministry of National Health Services Regulations and Coordination (MNHSRC), to improve testing capabilities, and is planning to expand further testing services. WHO has also established COVID-19 testing centers in eleven hospitals across the country in Pakistan.

Pakistan Health workers make individual sacrifices by serving and treating patients with negligeable care, even however they have the ethical responsibility for their individual safety in this pandemic. Due to the lack of appropriate equipment, the small number of medical establishments that provide COVID-19 provision, and the management's insufficient response to the crisis, frontline doctors and other health professionals have been working hard to the treatment of COVID-19 patients. Since the outbreak of the COVID-19 in Wuhan, China, many people have been killed, including health professionals. In Pakistan, there are doctors and health workers are extremely helpless to this fatal virus (World Bank, 2020a).

\subsection{Hazardous livelihoods}

The suspension of public services and daily activities and the health crisis have created economic emergencies. Approximately 55\% of the nation's population lives below the poverty line, and a considerable number of workers rely on informal work. The work stoppage formed a problem between saving lives and livelihoods. In Pakistan, out of the 65.5 million employed population, approximately 30 million are employed, of which 12 million are informally employed on a daily salary basis. Approximately 7.5 million informal workers are employed in the construction, transportation, trade, food and accommodation sectors every day, and these sectors are greatly affected due to spread of COVID-19 (Nizamani \& Muhammad, 2020).

Cotton textiles are the most important part of Pakistan's production, with the longest production chain, and its functions may increase value at every processing stage from cotton to ginning, spinning, fabric, dyeing and finishing to cosmetics and clothing. The industry subsidizes nearly a quarter of the industrial added value and provides employment opportunities for approximately 9 million industrial workers. With the spread of COVID-19 to developed countries (the main exporter of products made in Pakistan), these exports have declined since the outbreak of the COVID-19 crisis, and some orders have even been cancelled, putting the livelihoods of workers in this industry at risk.

The remaining manufacturing sector also employs 27.3 million workers, of which $75 \%$ are informal workers. Their employment conditions are no better than temporary workers. In addition, among a large proportion of self-employed persons, approximately 11.2 million employed persons in the familiar urban area live in danger (World Bank, 2020b). Therefore, the livelihoods of approximately 24.7 million people during the shutdown are ambiguous. Considering that the average family size is 4 people, about 55 million people are currently facing live- 
lihood challenges (Shafi et al., 2020).

The government of Pakistan has framed a 1.2 trillion Pakistani rupees economic recovery policy plan, which includes wages paid to export-oriented industries, credit for other jobs of various proportions, money for jobless persons, out of the country refugee labors and other small enterprises. Safety nets for the poor and distribution of cash and in-kind (Yezli \& Khan, 2020). However, the implementation records of many systems vary greatly, and the elements of large enterprises are considerable improved than those of small industrial enterprises. By means of protection actions, the transference the money to the deprived was insignificant and the performance procedure was blocked in collection and suspension. Therefore, it is not shocking that the frequency of poverty has increased significantly in various crises, as various studies have shown (Yezli \& Khan, 2020).

\subsection{Public and Social Distancing}

The social distancing is the main technique to avoid the decline spread of COVID19 disease (Cato et al., 2020). Since no recognized treatment is available, humans must keep a distance from one another in society to reduce the consequences of illness and death. In Pakistan, severe social isolation is becoming a significant and unsystematic for a large number of people who rely on the accessibility of regular labor. According to World Bank statistics, there are 207.8 million people living in Pakistan, 75.6 million in urban areas, and 16 million in informal urban areas such as slums. The family space for poor people living in slums in big cities is usually small-the average family size is about 5 , but in many cases it is larger.

Anwar (2020) reported that in Karachi slums, one third of the population live in one room with 5 to 7 members, while a quarter had 7 to 8 members sharing five rooms. Usually through narrow alleys to enter the living space in the slum, two people can hardly enter. In such an environment, even for those willing to obey, social distancing can be difficult. The poorest members of society, such as temporary workers, salesmen and rickshaw drivers, find themselves involuntary to interruption in social distancing in order to live (Piovani et al., 2020).

In the country's larger socio-economic background, social distancing is also questioned. The poor may have to line up to provide relief goods, buy cheap food provided by the government, and get cheap transportation. In addition to socioeconomic barriers, there are also sociocultural factors that may adversely affect compliance with social distancing rules. The condition is more complex when individuals move in crowded transportation during vacations and carnivals. Due to lack of access to appropriate information and public awareness, social distancing may also become a problem (Aragona et al., 2020). One more issue in keeping social distancing in religious rituals, which people often recur in difficult lives. People tend to participate in religious gatherings because religion gives people courage and an intellect of public consonance (Aragona et al., 2020). After lockdown, we observed two serious openings. One is the return of millions of 
cotton textile workers from all over the country to maintain their jobs, and the second is to participate in religious activities. Because of these insufficient administrative flaws, all sectors of society have criticized government officials ( $\mathrm{Fa}$ rooq et al., 2020).

\subsection{Distinct Clusters Need}

The worsening of physical and mental health has a serious harmful effect of the lockdown. Some new pressures caused by the continued spread of coronavirus have also increased mental and physical health threats (Nafees \& Khan, 2020). The old, incapacitated and immunocompromised patients, and severely ill patients are more affected (Sarkar et al., 2020). According to regional local media and public networks, domestic violence and gender disparity are on the escalation due to lockdown in various countries around the world. Professional women spend additional time doing household responsibilities with their regular professions, as several productions and administrations have shifted their work at home level. Reports from various countries show that the increase in domestic violence is alarming (Haq et al., 2020).

According to the latest report from a local NGOs group, there are at least 4734 women and 2224 children in 57 out of 130 districts in Pakistan experienced domestic violence in 2020. 1800 women and 524 children were subjected to violence for the first time in their lives. There are too reports that family quarrels have raised during this epidemic (Baig et al., 2020).

\section{Discussion}

The Government of Pakistan (GoP) has made many innovations to avert and control the spread of COVID-19 disease. Pakistan's MNHSRC has formulated the "Pakistan Preparedness and Response Plan for COVID-19." The key motive of the plan is to stop and control of the spread of COVID-19 disease. The government increased the number of ICUs, employed and proficient 6791 doctors, and 1360 health workers for provision and protection actions for frontline workers. Medical kits, PPE and other health aids for COVID-19 patients and medical staff are enhanced by the Government of Pakistan (GoP) (Waris et al., 2020). However, relative to other neighboring countries, Pakistan falls behind the percentage of patients to doctors and nurses and in medical facilities (Dhahri et al., 2020). In Pakistan, the main difficulty in treating people infected by COVID19 is the lack of adequate testing facilities of COVID-19 and lacking medical facilities. Therefore, the government should provide appropriate testing facilities and health services to fight this fatal disease.

Pakistan people struggling with difficult living conditions, the decisive decision is to face a fatal disease or starvation meanwhile they cannot get a job or wage. Many people prefer to get the former avoid hunger. For them, staying closed is not a daily choice. When they were forced to close down, many people ended up being helpless to go outside for work and lost salary. The government's 
support is deficient and unpropitious.

Later, many people became poorer and poorer. In the socio-economic and public situation where the Pakistan people live, social distancing practices are usually a major task. In addition, lack of awareness of spread of COVID-19, insufficient information, rude and social distancing practices are reasons that build the COVID-19 epidemic vast danger to the nation. At the similar period, poverty, malnutrition and distress of unemployment are actual reasons of helpless behavior.

To wear a mask is very significant. Wearing mask is the furthermost significant and authentic to help to restrict the increase spread of disease caused by COVID-19 virus. As stated by a report, $42 \%$ of Pakistan people wear protective masks. The statement also shows that approximately $32 \%$ of people in the Islamabad Capital Region wear protective masks to control the spread of infection (Chaudhry et al., 2020). It shows that people in city levels aren't following guiding principles for preventing the spread of disease. Therefore, encouraging and making people aware of the spread of this virus is a challenge for the government. For this reason, during this pandemic, strict measures to follow the SOPs could be followed to confirm agreement with Social distancing and wearing protective masks in civic spaces.

When relatives stick around jointly, domestic violence also increases. This happens in entirely community clusters. Women realize their inferiority complex being suppressed every day in their homes. As we all know, domestic violence against children and women in Pakistan is a solemn cultural problem. According to statistics from Pakistan Bureau of Statistics (PBS), 60\% of married women's partners have experienced domestic violence. Despite the regulations and consciousness, this is still a vast issue for women. Pakistan government must play a leading role in this fragment and provide prevention services for women suffering from such exploitation.

The findings of the research show that after the spread of COVID-19 the situations of the world population related to Pakistan has been changed. Due to spread of COVID-19 the vulnerable population is mostly affected. There have been low medical facilities in Pakistan, the unemployment has increased and the domestic violence against women and children has also increased simultaneously.

\section{Conclusion}

Formed on the occurrence with favor to the administration of the COVID-19 epidemic, a number of conclusions can be pinched. According to the data, COVID19 is spreading rapidly around the world. In just a few months, mortality and morbidity have reached unexpected levels. At the same level, Pakistan's population is fighting against this deadly virus. With this, Pakistan's medical care system is weak and facilities are low, and the government is not enough strong against the epidemic. Due to its health, social, economic and political structure, 
the Pakistani government will not be able to take any action against COVID-19.

Based on the administration knowledge of the COVID epidemic, many conclusions can be fagged out. Initial of all, careful policies are essential for controlling such a huge task. In addition to supposing that the duty isn't unchallenging, it is significant to be more careful. Additionally, it is important to take more resolute measures and more active implementation to prevent or decelerate the spread of coronavirus disease.

Next but one, considering that the weaknesses of the health system have not been protected by this practice, it is necessary to adopt existing practices to improve public health. In this case, it is vital to adopt appropriate arrangements, such as improving the equipment of medical facilities and training of workers. Actions should be drawn to ensure safe control of infection in hospitals to control the spread of COVID-19 infection. Pakistan's public health potential is weak, and different departments can jointly respond to the challenges brought by society and the participation of community.

\section{Recommendations}

To control the spread of infection, the Pakistan government's health and social policies must be strengthened. In this case, the following suggestions are made: Health facilities and testing services should be expanded. There is a need for better strategies between government strategy makers and local healthcare providers. Local facilities should take stabilization measures to ensure isolation from the society and wear masks in public places. In the implementation, great attention should be paid to government stimulus plans for the poor and low-income groups. The government and NGOs should participate and implement protection measures for women who have suffered violence and abuse.

\section{Authors Contributions}

All authors make equal contribution in this research and design. Material Preparation, data collection and analysis were performed by Tabassum Parveen, Wei Hao and Wenchang wang. The first draft written by Tabassum Parveen. All authors approved the final manuscript.

\section{Conflicts of Interest}

The authors have declared no competing interest.

\section{References}

Anwar, N. H. (2020). ns-urban slum. https://www.npr.org/sections/goatsandsoda/2020/04/06/827999804/social-distancing-is -a-distant-dream-in-pakistas? $\mathrm{t}=1610633311429$

Aragona, M., Barbato, A., Cavani, A., Costanzo, G., \& Mirisola, C. (2020). Negative Impacts of COVID-19 Lockdown on Mental Health Service Access and Follow-Up Adherence for Immigrants and Individuals in Socio-Economic Difficulties. Public Health, 186, 52-56. https://doi.org/10.1016/j.puhe.2020.06.055 
Baig, M. A. M., Ali, S., \& Tunio, N. A. (2020). Domestic Violence amid COVID-19 Pandemic: Pakistan's Perspective. Asia Pacific Journal of Public Health, 32, 525-526. https://doi.org/10.1177/1010539520962965

Cato, S., Iida, T., Ishida, K., Ito, A., McElwain, K. M., \& Shoji, M. (2020). Social Distancing as a Public Good under the COVID-19 Pandemic. Public Health, 188, 51-53. https://doi.org/10.1016/j.puhe.2020.08.005

Chaudhry, R., Dranitsaris, G., Mubashir, T., Bartoszko, J., \& Riazi, S. (2020). A Country Level Analysis Measuring the Impact of Government Actions, Country Preparedness and Socioeconomic Factors on COVID-19 Mortality and Related Health Outcomes. EClinicalMedicine, 25, Article ID: 100464. https://doi.org/10.1016/j.eclinm.2020.100464

Dhahri, A. A., Iqbal, M. R., \& Khan, A. F. A. (2020). A Cross-Sectional Survey on Availability of Facilities to Healthcare Workers in Pakistan during the COVID-19 Pandemic. Annals of Medicine and Surgery, 59, 127-130. https://doi.org/10.1016/j.amsu.2020.09.027

Farooq, F., Khan, J., \& Khan, M. U. G. (2020). Effect of Lockdown on the Spread of COVID-19 in Pakistan.

https://www.researchgate.net/publication/341507119 Effect of Lockdown on the spr ead of COVID-19 in Pakistan

Government of Pakistan (GoP) (2020). Coronavirus in Pakistan. Islamabad: Ministry of National Health Services Regulations \& Coordination. http://www.nhsrc.gov.pk

Gul, A. (2020). Pakistan Detects First Coronavirus Cases, Links to Iran Outbreak. https://www.voanews.com/science-health/coronavirusoutbreak/pakistan-detects-first-c oronavirus-cases-links-iran-outbreak

Haq, W., Raza, S. H., \& Mahmood, T. (2020). The Pandemic Paradox: Domestic Violence and Happiness of Women. PeerJ, 8, e10472. https://doi.org/10.7717/peerj.10472

Iqbal, M. A., \& Younas, M. Z. (2020). Public Knowledge, Attitudes, and Practices towards COVID-19 in Pakistan: A Cross-Sectional Study. Children and Youth Services Review, 120, Article ID: 105784. https://doi.org/10.1016/j.childyouth.2020.105784

Kakakhel, M. A., Wu, F., Khan, T. A. et al. (2020). The First Two Months Epidemiological Study of COVID-19, Related Public Health Preparedness, and Response to the Ongoing Epidemic in Pakistan. New Microbes and New Infections, 37, Article ID: 100734. https://doi.org/10.1016/j.nmni.2020.100734

Khalid, A., \& Sana, A. (2020). COVID-19 and Its Challenges for the Healthcare System in Pakistan. Asian Bioethics Review, 12, 551-564. https://doi.org/10.1007/s41649-020-00139-X

Nafees, M., \& Khan, F. (2020). Pakistan's Response to COVID-19 Pandemic and Efficacy of Quarantine and Partial Lockdown: A Review. Electronic Journal of General Medicine, 17, em240. https://doi.org/10.29333/ejgm/7951

Nizamani, S., \& Muhammad, S. W. (2020). Poverty and Inequality amid COVID-19Evidence from Pakistan's Labour Market. https://mpra.ub.uni-muenchen.de/id/eprint/100422

Piovani, D., Christodoulou, M. N., Hadji demetriou, A. et al. (2020). Effect of Early Application of Social Distancing Interventions on COVID-19 Mortality over the First Pandemic Wave: An Analysis of Longitudinal Data from 37 Countries. Journal of Infection, 82, 133-142. https://doi.org/10.1016/j.jinf.2020.11.033

Saqlain, M., Munir, M. M., Ahmed, A., Tahir, A. H., \& Kamran, S. (2020a). Is Pakistan Prepared to Tackle the Coronavirus Epidemic? Drugs \& Therapy Perspectives, 36, 1-2. https://doi.org/10.1007/s40267-020-00721-1 
Sarkar, A., Liu, G., Jin, Y., Xie, Z., \& Zheng, Z. J. (2020). Public Health Preparedness and Responses to the Coronavirus Disease 2019 (COVID-19) Pandemic in South Asia: A Situation and Policy Analysis. Global Health Journal, 4, 121-132. https://doi.org/10.1016/j.glohj.2020.11.003

Shafi, M., Liu, J., \& Ren, W. (2020). Impact of COVID-19 Pandemic on Micro, Small, and Medium-Sized Enterprises Operating in Pakistan. Research in Globalization, 2, Article ID: 100018. https://doi.org/10.1016/j.resglo.2020.100018

Waris, A., Khan, A. U., Ali, M., Ali, A., \& Baset, A. (2020). COVID-19 Outbreak: Current Scenario of Pakistan. New Microbes and New Infections, 35, Article ID: 100681. https://doi.org/10.1016/j.nmni.2020.100681

World Bank (2020a). https://blogs.worldbank.org/endpovertyinsouthasia/immediate-relief-pakistans-pande mic-stricken-poor

World Bank (2020b). https://www.worldbank.org/en/region/sar/coronavirus

Yezli, S., \& Khan, A. (2020). COVID-19 Social Distancing in the Kingdom of Saudi Arabia: Bold Measures in the Face of Political, Economic, Social and Religious Challenges. Travel Medicine and Infectious Disease, 37, Article ID: 101692. https://doi.org/10.1016/j.tmaid.2020.101692

Zhong, B. L., Luo, W., Li, H. M. et al. (2020). Knowledge, Attitudes, and Practices towards COVID-19 among Chinese Residents during the Rapid Rise Period of the COVID-19 Outbreak: A Quick Online Cross-Sectional Survey. International Journal of Biological Sciences, 16, 1745-1752. https://doi.org/10.7150/ijbs.45221 